\title{
Socioeconomic status and the career aspirations of Australian school students: Testing enduring assumptions
}

\author{
Jennifer Gore $\cdot$ Kathryn Holmes • Max Smith • \\ Erica Southgate $\cdot$ Jim Albright
}

Received: 15 October 2014/Accepted: 9 February 2015/Published online: 14 March 2015

(C) The Author(s) 2015. This article is published with open access at Springerlink.com

\begin{abstract}
Recent Australian government targets for higher education participation have produced a flurry of activity focused on raising the aspirations of students from low socioeconomic status (SES) backgrounds. In this paper we test two key assumptions underpinning much of this activity: that students from low-SES backgrounds hold lower career aspirations; and that outreach activities appropriately target secondary school students, given that younger students' aspirations are relatively under-developed. Drawing on a sample of 3,504 students, we map the intersection of the career aspirations of students in Years 4, 6, 8, and 10 with SES and other demographic variables in order to contribute to the evidence base for academic, educational, and political work on access to higher education and the policies, practices, and outcomes that might ensue. Aspirations are assessed in terms of occupational certainty, occupational choice, occupational prestige, and occupational justification. We found fewer differences by year level and by SES than expected. Our analyses demonstrate both the complexity of students' career aspirations and some of the challenges associated with undertaking this kind of research, thus signalling the need for caution in the development of policy and interventions in this field.
\end{abstract}

Keywords Equity - Higher education · Educational aspirations · Career aspirations $\cdot$ Socioeconomic status

\section{Introduction}

The educational and career aspirations of Australian school students have been of increasing interest to policy makers and university leaders especially during the past six years since the Review of Australian Higher Education, also known as the

J. Gore $(\bowtie) \cdot$ K. Holmes · M. Smith · E. Southgate · J. Albright

School of Education, University of Newcastle, University Drive, Callaghan, NSW 2308, Australia e-mail: jenny.gore@newcastle.edu.au 
"Bradley Review" (Bradley et al. 2008). We have seen a flurry of activity across schools and higher education institutions in relation to student aspirations, especially the aspirations of students from low-socioeconomic status (SES) backgrounds. Motivated by Bradley-inspired targets for $40 \%$ of all 25- to 34-year-olds in Australia to have a degree by the year 2025 and $20 \%$ of all university students to be from low-SES backgrounds by the year 2020 (Commonwealth of Australia 2009), as well as associated financial rewards for universities to meet their targets, activity focused on aspirations has been high. In 2011, for example, nearly $27 \%$ of funding from the Higher Education Participation and Partnerships Programme (HEPPP) was spent by universities on outreach initiatives, in various attempts to 'widen horizons' and pique students' interest in and sense of belonging to university education (Gale and Parker 2013; Naylor et al. 2013).

During this period there has been a significant increase in the number of domestic students enrolling in higher education overall and, most importantly from an equity perspective, an increase for students from low-SES backgrounds and Indigenous students greater than the overall expansion in the sector (Naylor et al. 2013), although still at levels far from equivalent to the representation of these groups in the population. Current figures for Australian universities suggest a ratio of around 0.62 for students from low-SES backgrounds and around 0.55 for Indigenous students, with 1.0 indicating parity (Naylor et al. 2013). These figures signal that there is much still to do if the key principle driving equity reform in higher education is to be met, namely that the participation in higher education of equity groups should match the distribution of such groups in the total population.

With entry to university impacted most by prior attainment, aspirations, awareness of the long-term benefits of higher education, and the need for financial, academic, or personal support once enrolled (Commonwealth of Australia 2009), there has been growing recognition that pathways to university or to other post-school destinations are often set well before Year 10 (15-16 years of age). Such recognition underpins the expansion of university outreach activities beyond the later years of high school into junior secondary and primary schools. And yet Year 10 remains the point in Australian schooling at which most careers education is provided (e.g., Cardak and Ryan 2009), the assumption being that it would be premature to commence careers education much earlier given that younger students tend to hold unrealistic or 'fantasy' aspirations (Gottfredson 1981; McMahon et al. 2001). However, we know comparatively little about the aspirations of younger students, with most studies of aspirations focusing on older adolescents (e.g., Bowden and Doughney 2010; Hawkins 2014; Marks et al. 2000). We also have limited insight into the complex ways in which aspirations change over the years of schooling.

Similarly, government policies and university outreach activities that target students from low-SES backgrounds, often framed in terms of 'raising' aspirations, are based on the assumption that these students have lower aspirations than their higher SES peers. It is true that low-SES students are under-represented in universities (Gale and Parker 2013; James 2002), but to what extent is this explained by differences in aspirations? We know relatively little about how career aspirations intersect with SES and other markers of social difference, especially across the years of schooling and across all SES categories. 


\section{Purpose of this study}

In this paper, we map the intersection of the career aspirations of students in Years 4, 6, 8, and 10 with SES and other demographic variables in order to contribute to the evidence base for academic, educational, and political work on access to higher education and the policies, practices, and outcomes that might ensue. Two sets of questions have guided this analysis:

1. How early do career aspirations take shape? How certain are students about what they want to do? What do they say they want to do? And for what reasons?

2. How do career aspirations vary by SES and other key markers such as gender, prior achievement, location, and year level?

We argue that this analysis is particularly critical in the shifting political context of fee deregulation, which is likely to make access to and participation in higher education harder again for students from low-SES backgrounds. Even if these students have aspirations for higher education and attainment levels that would make them eligible, they might find the long-term financial debt harder to re-pay and therefore might limit their enrolment in expensive degrees and careers of choice (Perry 2014). The proposed shift in policy_away from the Australian Labor party's uncapping of undergraduate places and provision of significant HEPPP funding and toward the elected Liberal government's plan to address equity through the provision of scholarships for the most 'capable' students-still depends in part on currently under-represented or 'non-traditional' students (Schuetze and Slowey 2002) aspiring to and choosing university. In this political context, understanding aspirations remains an important issue.

Our focus in this paper on students at different points in their schooling and from different backgrounds is designed to both illuminate the complex functioning of aspirations and disrupt potentially unfounded assumptions and conventional understandings. By examining the relationships of a range of demographic variables to aspects of career aspirations, we aim to provide rich data that can inform current and future debates.

\section{Methodology}

Data

The sample for this paper is drawn from data collected in the second year of our four-year longitudinal study, Educational and Career Aspirations in the Middle Years of Schooling: Understanding Complexity for Increased Equity. ${ }^{1}$ A purposeful sampling approach was utilised (McMillan and Schumacher 2009) in consultation with the NSW Department of Education and Communities to ensure variance with

\footnotetext{
1 The project is an Australian Research Council Linkage project (LP120100013) funded by the Australian Research Council and the NSW Department of Education and Communities.
} 
regard to SES and geographic location. The schools in the sample were categorised as $50 \%$ metropolitan and $50 \%$ provincial. The school-level Index of Community Socio-Economic Advantage (ICSEA) ${ }^{2}$ (Australian Curriculum, Assessment and Reporting Authority (ACARA) 2013) ranged from a low of 638 to a high of 1192, with a mean of 1002 and a standard deviation of 109, indicating that the distribution of our sample is representative of Australian schools overall, where the mean ICSEA value is 1000 and the standard deviation is 100 .

Clusters of one or two government secondary schools and between five and eight of their partner primary schools were identified. In each participating cluster of schools, all students in Years 4, 6, 8, and 10 (in 2013) were potential participants. The data were obtained from surveys completed by 3,504 students from Years 4 $(n=853), 6(n=985), 8(n=976)$, and $10(n=674)$ (16 students did not provide a year level) from 59 schools in New South Wales (NSW) (43 primary, 13 secondary, and 3 central [K-12] schools, including one Catholic secondary school already partnering with the local government schools). The sample contained equal proportions of females $(n=1,732)$ and males $(n=1,730)$. In addition to the survey data, we accessed National Assessment Program Literacy and Numeracy (NAPLAN) results and demographic data for each student.

\section{Measures of aspirations}

For this paper, we wanted to investigate different aspects of aspirations. First, in order to test whether younger children's aspirations are less well formed and more tentative than those of older students we developed a measure of occupational certainty, or the degree to which students expressed firm occupational or career goals. Next, given the discourse of raising aspirations and related notions of 'high' and 'low' aspirations, as well as the link between university education and more prestigious occupations, we utilised a measure of occupational prestige. Finally, to enable more fine-grained analysis, we looked at the specific occupational choices made by students and their reasons or justifications for their choices; we call this occupational justification. Our methods for determining each of these are outlined below.

\section{Occupational Certainty}

Students were asked in the survey if they knew what kind of work they wanted to do when they grew up. If they answered 'yes', they were then asked to name the kind of work (in an open-ended question) and their reasons for choosing it. If they answered 'no', they were asked for some of the kinds of work or specific jobs they had thought about doing (if any). These questions allowed us to categorise the students into three groups based on certainty about their future occupation: those who expressed a definite idea of a future career; those who expressed a tentative idea for a future career; and those who expressed no specific career interest.

\footnotetext{
${ }^{2}$ ICSEA is the Index of Community Socio-Educational Advantage created by ACARA to enable meaningful comparisons of NAPLAN test achievement by students in schools across Australia.
} 


\section{Occupational Prestige}

Where students provided either a definite or tentative occupation, their openended responses were coded according to the Australian and New Zealand Standard Classification of Occupations (ANZSCO) (Trewin et al. 2006). The ANZSCO codes were then converted into the Australian Socioeconomic Index 2006 (AUSEI06) (McMillan et al. 2009), which is an occupational status scale ranging from 0 (the lowest status) to 100 (the highest status). The AUSEI06 also includes measures of education in its calculation. Aspirations coded in the firstthird of the scale encompass non-skilled and semi-skilled occupations such as labourers, sales assistants, receptionists, and hairdressers. Those coded in the second-third of the scale represent skilled and paraprofessional occupations like tradespersons, police officers, and human resource officers. Finally, those coded in the top-third include professional occupations such as teachers, lawyers, accountants, and medical practitioners. Students were categorised as low, middle, or high aspiring, based on the thirds identified above. When students provided more than one occupational choice, the most highly ranked occupation was used.

\section{Occupational Justification}

Textual responses to the question "Why do you want to do this work?" were read individually and emerging themes were noted. Only those students who indicated certainty for a desired occupation $(n=2,474)$ were included in this analysis. Twenty themes were identified through the coding process. The five most prevalent themes formed the data for analysis of relationships between occupational justification and the demographic measures outlined below.

Demographic measures

The major demographic measures of interest for this analysis were SES and school year (Year 4, 6, 8, 10). Given differences within any SES category, and the findings of prior studies (Dalley-Trim 2012; Kilpatrick and Abbott-Chapman 2002; McMahon and Rixon 2007), we also considered gender and school location. Year level and gender were accessible from school enrolment records provided by the NSW Department of Education and Communities. Location was classified as metropolitan or provincial, using the Schools Geographic Location Classification Scheme reported in the MySchool website. ${ }^{3}$ Our method for determining SES is outlined below, together with our approach to providing a measure of prior achievement.

\footnotetext{
${ }^{3}$ See http://www.myschool.edu.au/AboutUs/Glossary/glossaryLink. None of the schools participating in the study fell in the remote zone in the Schools Geographic Location Classification Scheme reported in the MySchool website.
} 
Individual student SES was calculated using data sourced from school enrolment forms. Parental level of education was represented by an ordinal variable coded 1 (Year 9 or equivalent or below), 2 (Year 10 or equivalent), 3 (Year 11 or equivalent), 4 (Year 12 or equivalent), 5 (Certificate I-IV including trade certificate), 6 (Advanced diploma/Diploma), or 7 (Bachelor degree or above). Parental occupation was represented by an ordinal variable coded 1 (not in paid work in last 12 months), 2 (machine operators, hospitality staff, assistants, labourers, and related workers), 3 (tradesmen/women, clerks and skilled office, sales and service staff), 4 (other business managers, arts/media/sportspersons, and associated professionals), or 5 (senior management in large business organisations, government administration and defence, and qualified professionals). These categories are consistent with the data standards for student background characteristics prescribed for nationally consistent reporting by schools, school systems, test administration authorities, and assessment contractors (ACARA 2012).

The approach taken was to combine these variables into an equally weighted composite score consistent with the approach of Marjoribanks (2003) and Khattab (2005). These are not mandated fields on the enrolment form and there is a relatively high incidence of missing data which in some cases rendered it impossible to calculate this SES measure. To minimise data loss, the decision was taken to base student SES on the highest educational level and the highest occupational status in each family. Full data for the NSW government school sector was used as a normative backdrop to separate SES scores into quartiles for later analysis.

\section{Prior achievement}

The students in this study were in Years 4, 6, 8, and 10 at the time these data were gathered. To enable a comparable measure of prior achievement their individual NAPLAN results from Years 3, 5, 7, and 9 were accessed. Attainment in NAPLAN was taken as the equally weighted composite of individual student Reading and Numeracy scores. Full data for the NSW government school sector was used as a normative backdrop within each year level to separate student NAPLAN scores into quartiles and percentiles where used.

\section{Analysis}

Separate analyses were conducted in relation to occupational certainty, occupational choice, occupational prestige, and occupational justification.

\section{Occupational Certainty}

With three possible outcomes (Certain, Tentative, and Unformed) and thus a categorical variable, multinomial logistic regression was conducted using SPSS to analyse the dependent variable, occupational certainty. Prior achievement and SES were represented through a series of dummy variables contrasting the effects of 
being in quartiles 1,2 , and 3 with the highest quartile, quartile 4 (the omitted category). This allowed the odds ratios for the successively higher quartiles to be presented and interpreted in the same way as the odds ratios for the other independent variables in the model. The other independent variables included location (provincial $=0$, metropolitan $=1)$; sex $($ male $=0$, female $=1$ ); year level $(4,6,8,10)$; and, educational intent (high school, TAFE, university).

\section{Occupational Choice}

Descriptive analysis was undertaken on the responses of the students who gave a Certain or Tentative job choice. Between-group comparisons of the rankings of the most frequently named occupations were conducted across categories by gender, location, SES quartile, NAPLAN quartile, and school year level.

\section{Occupational Prestige}

Given the occupational prestige scale (AUSEI06) with its range from 0 to 100 as described earlier, a multiple linear regression analysis was conducted to determine the extent of the partial relationships between occupational prestige and other student variables (year level, prior achievement, SES, gender, and location). Students providing a Certain or Tentative job choice produced a sample of 3,196 for this analysis.

The need for multilevel analysis to capture between-school differences as compared with between-student differences in the prestige of students' occupational choices was also tested. The two-level null model examined student-level variance at level 1 and school-level variance at level 2. This revealed that the proportion of variance accounted for at the school level was $5.5 \%$ of the total variance in the prestige of students' occupational choices. School-level variances of this magnitude generally indicate that multilevel effects will be trivial (Lee 2000; Preacher et al. 2011).

\section{Occupational Justification}

Emerging themes in the occupational justification data were discussed among researchers and categories (nodes) were identified through inductive coding (Thomas 2003) using NVivo. Responses were coded for all relevant nodes and, in order to enhance reliability, nodes were discussed and refined throughout the coding process. These nodes were identified by a descriptive word or phrase, taken from the particular wording used by students. All nodes were exported from NVivo into SPSS for further statistical analysis.

\section{Results}

\section{Occupational Certainty}

Of the 3,504 students, 2,474 (71\%) stated that they knew what kind of work they wanted to do and then stated a specific occupation (the 'Certain' job outcome). 
Another $722(21 \%)$ initially responded that they did not know what kind of work they wanted but provided a tentative occupation when prompted a second time (the 'Tentative' job outcome). Only 289 students (8\%) responded that they did not know what job they aspired to and did not provide any tentative suggestions (the 'Unformed' job outcome). Nineteen cases had missing responses.

The multinomial regression showed a significant relationship, $p<.01$, between occupational certainty and the independent variables with the full model. The fit statistics for the default model against the full model, and the significance of the relationship associated with each independent variable are reported in Table 1. Year level, prior achievement, educational intent, and SES were significant in accounting for the occupational certainty of students.

Table 2 presents the relative odds ratios for Certain (the reference category) compared in turn with the Tentative and Unformed categories. While growing in popularity as an analytical approach, the results obtained through logistic regression are notoriously difficult to interpret and frequently misunderstood (Osborne 2006). One approach to assist interpretation is to include a common language description of the effect size. Here we use Monson's (1990) common language description of effect sizes for odds ratios to indicate the substantive importance of each statistically significant parameter (Robinson and Levin 1997). For example, the relative odds of Year 4 students being tentative about their job choices are moderately lower $(\mathrm{OR}=.43)$ than those of Year 10 students. The chances of being tentative increase slightly for Year 6 students $(\mathrm{OR}=.56)$ but are still moderately lower than those of Year 10 students. The non-significant result for the Year 8 group indicates that the relative odds of making a tentative job choice are statistically

Table 1 Occupational certainty, default model against full model and effects for reduced model

\begin{tabular}{|c|c|c|c|c|}
\hline & \multirow{2}{*}{$\begin{array}{l}\text { Model Fitting Criteria } \\
-2 \text { Log Likelihood of Reduced Model }\end{array}$} & \multicolumn{3}{|c|}{ Likelihood Ratio Tests } \\
\hline & & Chi Square & $\mathrm{df}$ & Sig. \\
\hline \multicolumn{5}{|l|}{ Likelihood Ratio Tests } \\
\hline \multicolumn{5}{|l|}{ Full model } \\
\hline Intercept Only & 1581.56 & & & \\
\hline Final & 1470.97 & 110.59 & 26 & .000 \\
\hline \multicolumn{5}{|c|}{ Effects-reduced model } \\
\hline Intercept & $1470.97^{\mathrm{a}}$ & .00 & 0 & \\
\hline Location & 1473.88 & 2.92 & 2 & .23 \\
\hline Year level & 1508.27 & 37.30 & 6 & .00 \\
\hline Prior achievement & 1501.71 & 30.75 & 6 & .00 \\
\hline Sex & 1473.25 & 2.28 & 2 & .32 \\
\hline Educational intent & 1491.88 & 20.91 & 4 & .00 \\
\hline SES & 1490.75 & 19.79 & 6 & .00 \\
\hline
\end{tabular}

a This reduced model is equivalent to the final model because omitting the effect does not increase the degrees of freedom 
Table 2 Occupational certainty, parameter estimates

\begin{tabular}{|c|c|c|c|c|c|c|}
\hline \multirow[t]{2}{*}{ Occupational Certainty ${ }^{\mathrm{a}}$} & \multicolumn{3}{|c|}{ Tentative } & \multicolumn{3}{|c|}{ Unformed } \\
\hline & Sig. & Odds Ratio & Effect $^{\mathrm{c}}$ & Sig. & Odds Ratio & Effect $^{\mathrm{c}}$ \\
\hline \multicolumn{7}{|l|}{ Parameter Estimates } \\
\hline Intercept & .000 & & & .000 & & \\
\hline \multicolumn{7}{|l|}{ Year level } \\
\hline Year 4 & .000 & .43 & Moderate & .009 & .47 & Moderate \\
\hline Year 6 & .000 & .56 & Moderate & .262 & .75 & \\
\hline Year 8 & .476 & .89 & & .371 & .79 & \\
\hline Year 10 & & $\mathrm{~b}$ & & & $\mathrm{~b}$ & \\
\hline \multicolumn{7}{|l|}{ Prior achievement } \\
\hline Quartile 1 & .000 & .49 & Moderate & .003 & .38 & Strong \\
\hline Quartile 2 & .000 & .54 & Moderate & .000 & .36 & Strong \\
\hline Quartile 3 & .003 & .64 & Moderate & .028 & .60 & Moderate \\
\hline Quartile 4 & & $\mathrm{~b}$ & & & $\mathrm{~b}$ & \\
\hline \multicolumn{7}{|l|}{ Educational intent } \\
\hline High School & .007 & 1.60 & Moderate & .000 & 2.56 & Moderate \\
\hline TAFE & .260 & .82 & & .768 & 1.09 & \\
\hline University & & $\mathrm{b}$ & & & $\mathrm{b}$ & \\
\hline \multicolumn{7}{|l|}{ SES } \\
\hline Quartile 1 & .151 & 1.28 & & .798 & 1.08 & \\
\hline Quartile 2 & .141 & .78 & & .917 & .98 & \\
\hline Quartile 3 & .050 & .72 & Weak & .024 & .52 & Moderate \\
\hline Quartile 4 & & $\mathrm{~b}$ & & & $\mathrm{~b}$ & \\
\hline
\end{tabular}

${ }^{a}$ The reference category is: Certain

b This parameter is set to zero as it is the omitted category

${ }^{c}$ Description of effect size from Monson (1990)

equivalent for students in Years 8 and 10. In comparison to those students who are intending to go to university, those who are not planning any post-school education are moderately more likely to be tentative about their occupational choice $(\mathrm{OR}=1.60)$. Furthermore, in comparison to students in the highest achievement quartiles, students in the other three quartiles are less likely to be tentative in their occupational choice (ORs ranging from .49 to .64). The smallest significant effect in the model was for students in SES quartile $3(\mathrm{OR}=.72)$ indicating that students in this quartile were slightly less likely to make a tentative job choice than the students from higher SES backgrounds in quartile 4.

The strongest effects in the model occurred in the Unformed category for prior achievement quartiles 1 and 2 (.38 and .36, respectively). The results here show that students in the lower prior achievement quartiles are less likely to indicate an unformed job choice. All other statistically significant effects relating to the unformed job choice category were moderate or weak where they existed. These included Year 4 students $(\mathrm{OR}=.47)$, students in prior achievement quartile 3 


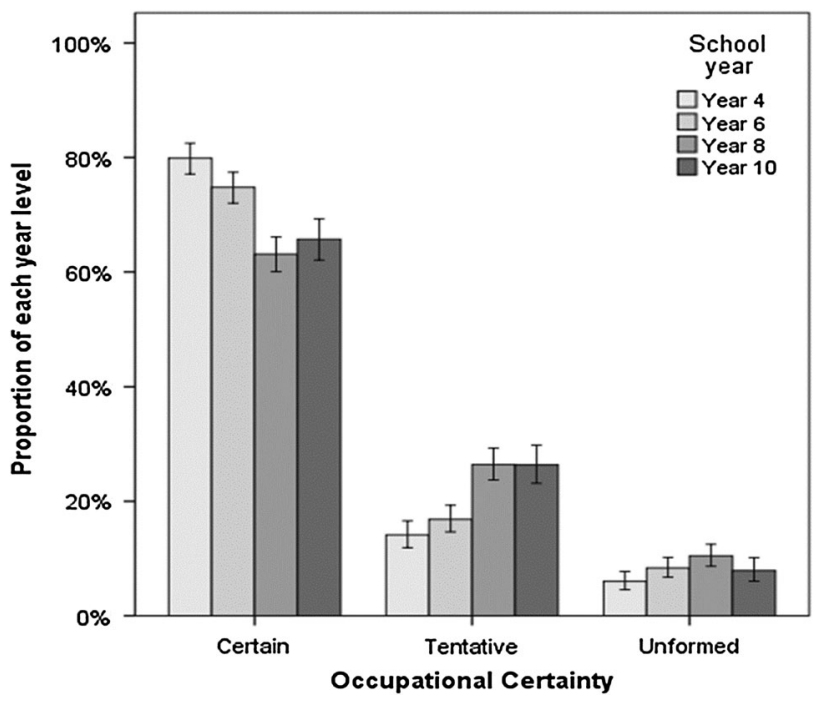

Fig. 1 Occupational certainty by year level

$(\mathrm{OR}=.60)$, and students in SES quartile $3(\mathrm{OR}=.52)$ being moderately less likely, and students who indicated an intention to finish their education after secondary school being moderately more likely $(\mathrm{OR}=2.56)$ to indicate an unformed job choice.

While overall statistical significance exists with respect to the key model fit statistics and four of the six parameter estimates in the reduced model (see Table 1), the overall model was relatively poor in terms of its explanatory and predictive power. To help guard against possible over-interpretation of the parameter estimates in the fitted model, Figs. 1, 2, 3, and 4 illustrate the variation in occupational certainty in raw percentages across categories with the associated $95 \%$ confidence intervals for the statistically significant explanatory variables.

\section{Occupational Choice}

The responses of the students who gave a Certain or Tentative job choice were collated and the five most frequently named occupations by gender, location, SES quartile, NAPLAN quartile, and school year level are presented in Table 3. Across all student groupings, only 11 occupations were named among the five most highly ranked. Listed in prestige order from low to high (using AUSEI06), these were mechanic, animal trainer, defence force, sportsperson, police officer, entertainer, engineer, school teacher, psychologist, vet, and doctor. Sportsperson, teacher, and vet appeared among the top five occupations for nearly every student group, with the exceptions being that sportsperson was not ranked in the top five for girls (instead ranked 11th) and school teacher and vet were not in the top five for boys (ranked 7 th and 11th respectively). 


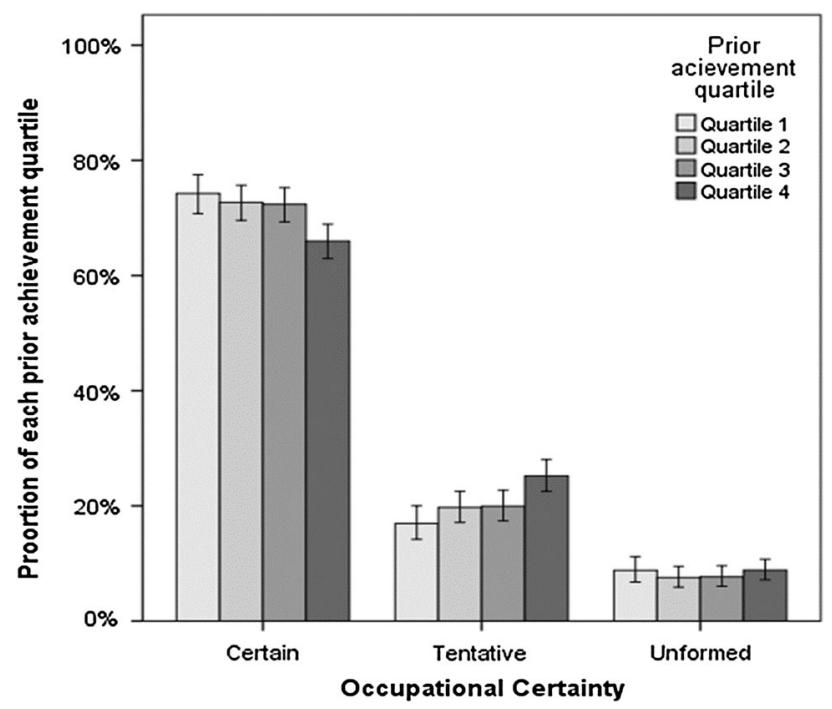

Fig. 2 Occupational certainty by prior achievement quartile

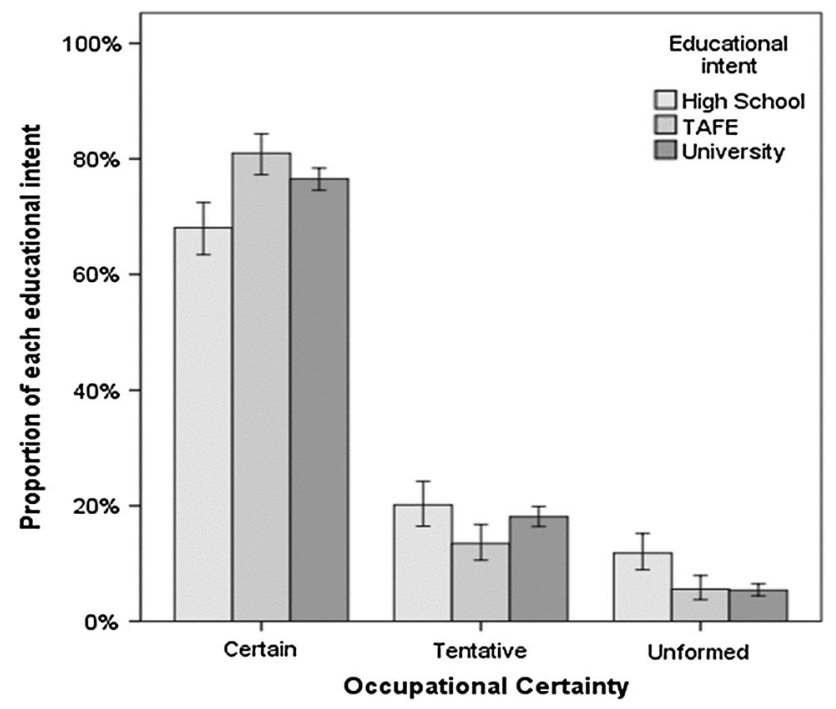

Fig. 3 Occupational certainty by educational intent

A small number of occupations were ranked in the top five for only a small number of student groups. These were mechanic (only popular with boys, low SES, and Year 10), defence force (only boys and Year 10), engineer (only boys and Year 8), psychologist (only Year 10) and doctor (only girls, high SES, and high achievement). There was no overlap in the top five occupations for boys when compared with girls' top five occupational choices. 


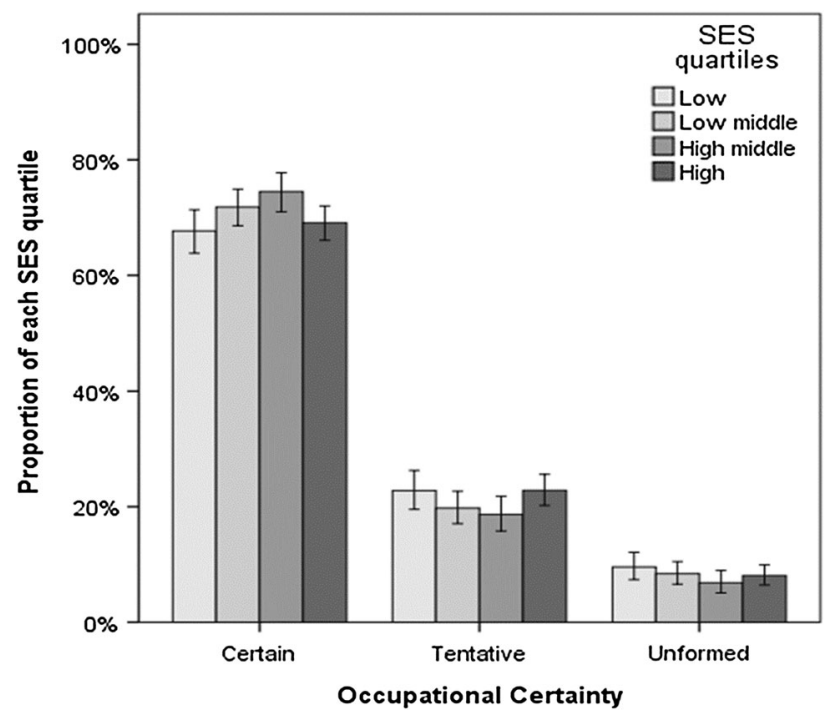

Fig. 4 Occupational certainty by socioeconomic status (SES)

\section{Occupational Prestige}

The partial relationship between occupational prestige and the independent student variables (year level, prior achievement, SES, gender, and location) was assessed using multiple linear regression. All variables, except location, were significant. The final fitted model after omitting location explained $13 \%$ of the variance in the occupational prestige score $\left(F(4,2562)=96.94, p<.01, R^{2}=.13, R_{\text {adjusted }}^{2}=.13\right)$. The regression statistics are presented in Table 4.

The regression output indicates that when all variables are considered in terms of their partial contributions, student prior achievement $(\beta=.27$ ) (assessed in this part of the analysis as percentile ranks within year levels) was most strongly related to the occupational prestige score, followed by gender $(\beta=.17)$, SES $(\beta=.09)$ (assessed here as a continuous variable), and year level (a very modest but significant $\beta=.05$ ).

To consider the practical significance of these differences, the mean prestige score for each of the groupings by year level, prior achievement, and SES were calculated and are presented in Fig. 5. Overall, these data indicate differences within a narrow range, with most of the means hovering around the top of the middle third of occupations, between skilled/paraprofessional occupations and professional occupations. Figure 5 also reinforces the stronger relationship of prior achievement with occupational prestige, followed by SES and year level.

\section{Occupational Justification}

The occupational justifications written by students who provided a definite job aspiration were coded into categories with the five most prevalent themes listed below, together with some examples. For each example, the student is identified by 


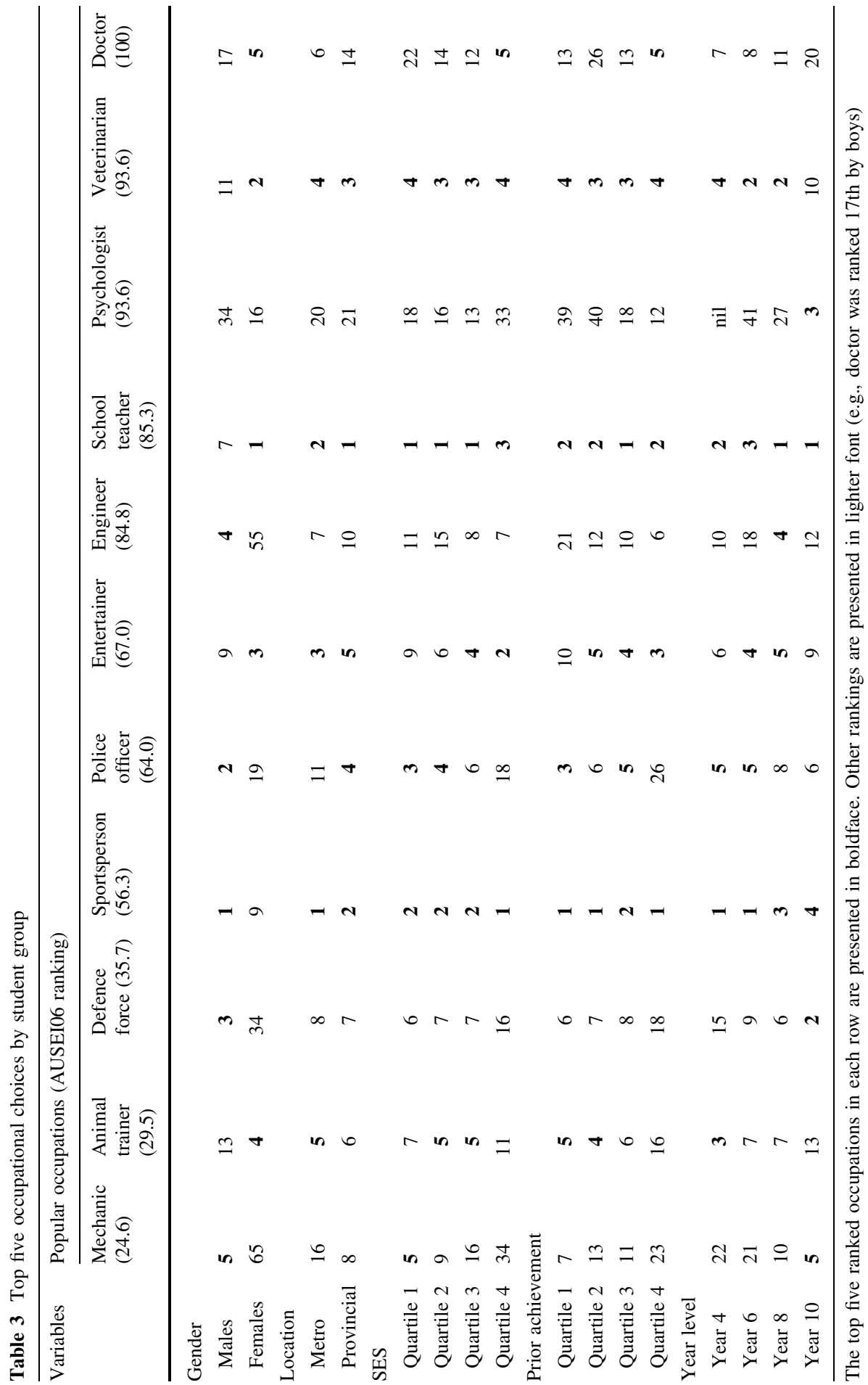


Table 4 Summary of regression analyses for variables predicting the prestige of students' occupational choices

All effects were significant at the .01 level

\begin{tabular}{lccc}
\hline Variables & \multicolumn{3}{l}{ Occupational Prestige } \\
\cline { 2 - 4 } & B & SE B & $\beta$ \\
\hline Year level & 1.11 & .39 & .05 \\
Prior achievement & 5.52 & .42 & .27 \\
SES & .14 & .06 & .09 \\
Gender & 5.42 & .88 & .17 \\
$R^{2}$ & .13 & & \\
$F$ & 96.94 & & \\
\hline
\end{tabular}

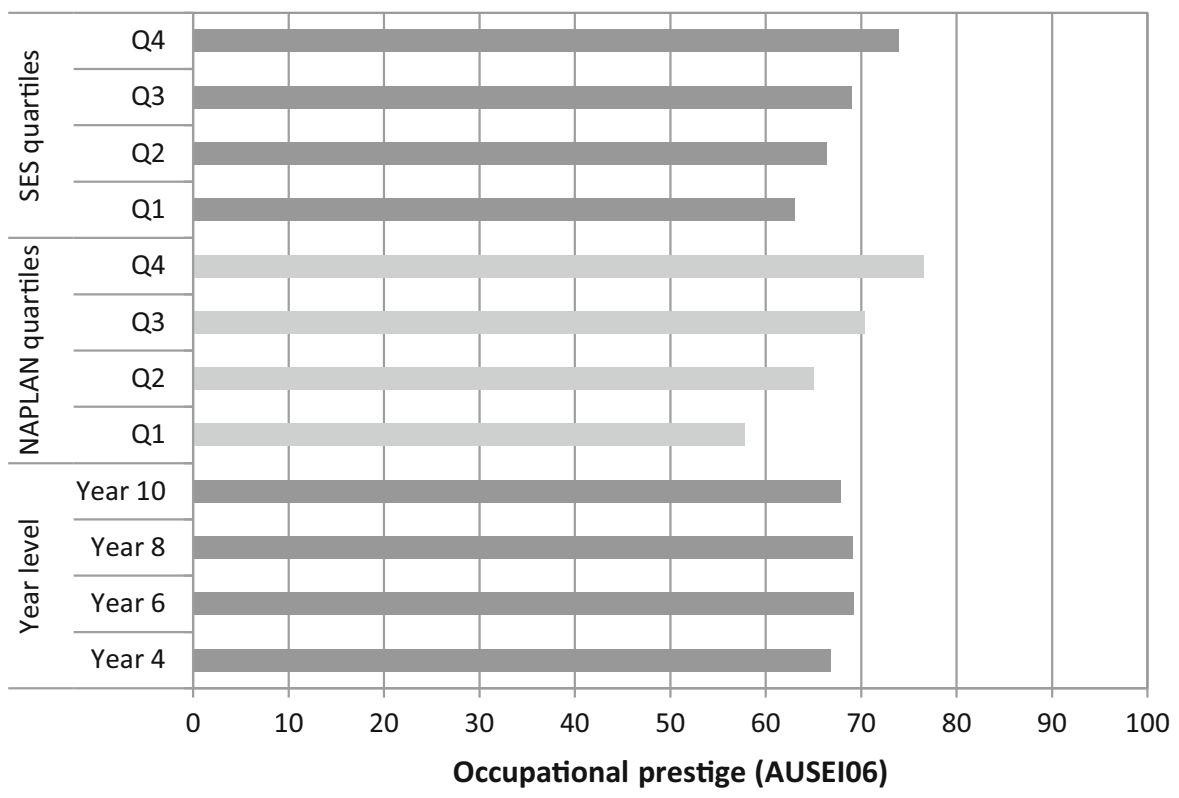

Fig. 5 Mean occupational prestige by student group

gender, school sector (primary/secondary), SES, prior achievement, and occupational prestige tertiles (low, mid, high).

1. The job is related to something that they like or love $(n=803$ or $32.4 \%$ of students):

I love art and I love the sea, I can't stand to let animals die. I would like to study the ocean till my arms and legs can't swim anymore. (female, primary, low SES, high achievement, high aspiration)

Because I love the human bones and i [sic] love crime so together it's the perfect job. (female, secondary, mid SES, high achievement, high aspiration) 
2. They think they will be good at or are interested in that kind of work ( $n=408$ or $16.4 \%$ of students):

This field of work [astronomy] has always interested me. I dream of working in this field of work. I believe that in this field of work I can show my full potential. (male, secondary, high SES, high achievement, high aspiration) I want to do this because I enjoy having an education and I would love to help future kids with there [sic] future education. I have also got the academic award 2 years in a row so learning new stuff comes easy to me. (female, primary, mid SES, mid achievement, high aspiration)

3. The job involves helping others in some way ( $n=351$ or $14.2 \%$ of students): I have always been interested in helping people, and being a doctor sounds like a really good job to have. (female, secondary, low SES, high achievement, high aspiration)

I would like to do this job to save animals' lives. (female, primary, low SES, low achievement, high aspiration)

4. They think the job would be fun, enjoyable, or exciting ( $n=327$ or $13.1 \%$ of students):

Because engineering is something I enjoy, and I have a family history in the $\mathrm{ADF}^{4}$. (male, secondary, mid SES, high achievement, high aspiration)

5. The job would earn them lots of money ( $n=192$ or $7.7 \%$ of students):

I love computers and engineering is a good, high paying job. (male, secondary, mid SES, high achievement, high aspiration)

These five most prevalent themes accounted for three-quarters of the 2,754 coded justifications given by the 2,474 students who provided a reason or reasons for their occupational choice. These five themes were examined further in relation to the other key variables: year level, SES, prior achievement, gender, and location (using Chi square or $t$ tests as appropriate). Table 5 summarises the percentage of students in each group who provided a reason identified within the relevant theme, as well as the direction of all statistically significant relationships found. Empty cells signify no significant difference.

Students in the primary years more often reported 'like or love' as the reason for selecting their preferred occupation, as did students in the highest SES quartile and females. While less frequently reported overall, being 'good at or interested in' as the reason for selecting their job preference was more frequently chosen by secondary students, high SES students, and higher achieving students. 'Altruism' was more frequently reported by students in the middle-SES quartiles and considerably more often by female students. Year 10 students reported 'fun or excitement' as the reason for the job choice more frequently than younger students. While less frequently reported overall, 'money' was reported more frequently as the

\footnotetext{
${ }^{4}$ Australian Defence Force.
} 


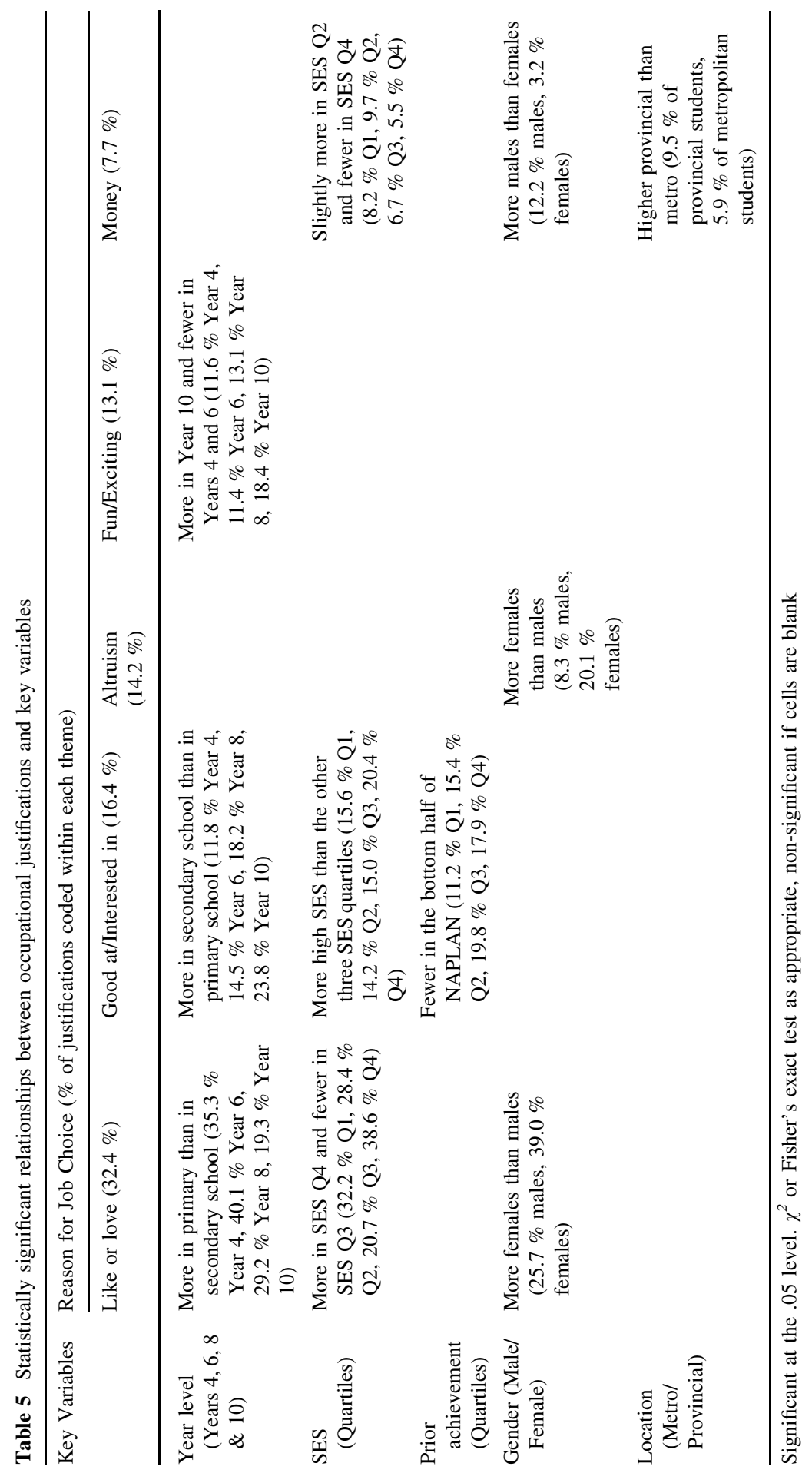


reason for selecting their preferred occupation by provincial students and lower SES students, and considerably more frequently by male students.

\section{Discussion}

Beyond conventional understandings of year level and aspirations

The vast majority of research, policy, and practice pertaining to student aspirations has focused on understanding and supporting the educational and career aspirations of students in the last three years of secondary school. This focus is based on when students are understood to make decisions about their post-school destinations, given that their final school subject selections are made around that time, as well as conventional understandings of their readiness for doing so. And yet we found that the aspirations of younger students were similar in many respects to those of older students. There was substantial commonality in the specific occupations favoured by younger and older students (Table 3), and only a weak relationship between year level and occupational prestige (Table 4), with older students choosing slightly more prestigious occupations. The practical significance of this difference in occupational aspirations is very low (Fig. 5), with only 2.4 points on the 100-point occupational prestige scale separating the mean scores of the four year levels.

In examining occupational justification there was no difference between younger and older students in the proportion providing altruistic or financial reasons, while secondary school students more often justified their choices based on their interests and strengths (Table 5). The main difference between younger and older students was, somewhat counter-intuitively, that primary school students were significantly less tentative about careers they might pursue than students in secondary school (Fig. 1).

These findings raise questions about the current emphasis on aspirations in the later secondary years in most Australian schools. For example, a 2014 Australian Government call for development of a critical interventions framework for advancing equity in Australian higher education identifies 'later years outreach' rather than early years outreach as a priority. While the tentativeness of students' career plans at Year 10 might reinforce the need for support in career planning at this point in schooling (with nearly $40 \%$ tentative or undecided), it is not clear that students are either ready to make firm decisions or need to. Our data on occupational justifications suggest that the older students were drawing on the dominant discourses of career education that encourage students to 'know' themselves, to identify their strengths and interests, in order to find careers matched to their individual 'capacities'. Instead of the urgent focus on selecting a career, the focus of career education could shift towards students' reasons for wanting particular careers, which could then lead them to consider ways in which a range of careers might bring similar 'payoffs'. For example, with the under-representation of girls in engineering, knowing that altruism underpins the occupational choices of a significant number of girls could mean exploring with girls the ways in which engineering helps people and communities, as one part of their occupational 
decision-making. The suggestion here is not so much fitting the individual to a narrow range of careers that suit his or her interests, but opening up the range of possible careers by exploring how those careers might fit the individual.

Furthermore, the minor differences we found across year levels suggest scope to explore students' occupational futures as part of their education at an earlier age. We are not advocating a simple replication of dominant approaches to careers education in the primary school but there might be value in discussions focused on motivations, pathways, and options. This approach counters developmental theories of aspiration formation that have viewed younger children's career aspirations as based in fantasy, or as unrealistic, and therefore not taken seriously. Fantasy occupations have been defined as career choices based solely on interests and desires with no reference to ability, such as high-status jobs (doctor, lawyer, etc.) that require tertiary education, or jobs such as musician or sportsperson that may not be realistic in terms of children's abilities (Ginzberg 1952; Gottfredson 1981; McMahon et al. 2001). But who is to judge whether these career interests are 'fantasies', for whom, and at what point? Using a more literal notion of fantasy, of the occupations named by more than 3,000 students across our whole sample, only two students named careers that were 'not real'- 'superhero' and 'king of the world'. From as early as Year 4, the vast majority of students expressed interest in 'real' occupations. Most did so with a reasonable level of certainty (71\% certain, or $92 \%$ tentative or certain) and mostly their career aspirations were classified as middle to high prestige.

In any case these data call into question the focus on 'raising' aspirations. As others have argued, the greater concern is to maintain aspirations (e.g., Cummings et al. 2012). In addition, we are proposing that it might be important to think about aspirations more broadly than the prestige score and necessary educational attainment associated with a particular job. Our data on occupational justifications suggests value in considering the reasons expressed by students for their occupational choices in order to broaden the range of possible careers with potential for fulfilling their hopes, interests, and desires.

Beyond conventional understandings of SES and aspirations

Given the under-representation of students from low-SES backgrounds in universities and high prestige occupations that has underpinned equity policy in higher education, we were particularly interested in the interaction of SES with occupational certainty, prestige, choice, and justification. Looking broadly at SES, ${ }^{5}$ we found weak and moderate associations (respectively) with tentative and unformed job choices (Table 2), and a relatively weak relationship with occupational prestige, with higher SES students expressing interest in slightly more prestigious occupations (Table 4). In practical terms however, this difference between the mean scores of the lowest and highest SES quartiles was only 10 points

\footnotetext{
5 It has not been within the scope of this paper to tease out the relationships among the key variables examined, such as how aspirations differ for low- and high-SES girls, or low- and high-SES students living in metropolitan and provincial areas, however we will address these intersections in subsequent analyses.
} 
on the 100-point prestige scale, indicating relatively small differences in occupational type (Fig. 5). That is, the vast majority of students across all SES quartiles were interested in professional or skilled/paraprofessional occupations. Indeed, across the SES quartiles, vet, teacher, and sportsperson were consistently ranked among the top five occupations (Table 3). The impact of SES was most apparent in the career choices of doctor, which only appeared in the top five for students from high-SES backgrounds, and mechanic, only in the top five for students from low-SES backgrounds. SES also produced some significant differences in occupational justification, with high-SES students more often citing interest and passion as motivations behind their career choices and lower SES students more often citing money.

While the differences by SES were relatively small, we do not want to suggest that SES is unimportant or that additional support is not needed for students from low-SES backgrounds. The stronger financial motivation of students from low-SES backgrounds signals their hopes for occupational futures that provide financial security, while students from higher SES backgrounds appeared to see greater scope for pursuing their interests and passions. Taking into account that these data included students in Years 4, 6, 8, and 10, we have evidence of the formation of aspirations and differences by SES, as early as nine years of age.

These results emphasise the importance of education in ensuring that a broad range of possibilities remains available to all students, including those from lowSES backgrounds (Atherton et al. 2009; Tough et al. 2008). Knowing that achievement in schooling represents the cumulative histories of students' prior achievement, as well as their lives outside school, these data remind us of education's critical role in overcoming rather than reproducing societal inequalities. Whilst analyses of the educational achievement of Australian students through international assessments like PISA consistently show that low-SES students are lower achieving, there is more to be done in supporting the educational achievement of these students in order to achieve their access to a full range of careers. This is particularly true given the significant role of prior achievement in shaping aspirations (Baker et al. 2014; Gorard et al. 2012).

The significant role of prior achievement

In all of our analyses, prior achievement was stronger than SES in explaining students' aspirations. Students with higher prior achievement expressed less certainty about their occupational aspirations, likely signalling the greater range of options available to them and a lack of urgency in selecting a definite career path. Higher prior achievement was also the strongest factor in explaining aspirations for more prestigious occupations and also distinguished students who provided justifications for their occupational choices based on interest in or being good at a particular discipline or field.

These findings reinforce the idea that 'expanding' or 'raising' the aspirations of students from low-SES backgrounds might not be the key strategy for increasing equity in higher education. Instead greater emphasis on supporting the educational achievement of students from these backgrounds is likely to be more critical and 
more effective in recruiting a greater proportion of non-traditional students to universities.

\section{Unexplained variance}

Despite the differences among groups found in our analyses, we reiterate that only $13 \%$ of the variance in occupational prestige was accounted for by the combined effects of prior achievement, gender, SES, and year level (and location was not significant in any of our analyses, with the exception of more provincial students citing money as a reason for their occupational choices). This means that the greater part of the variance in occupational choice and prestige is accounted for by other factors. We speculate that occupational aspirations as expressed in the career choices of individual students have more to do with the specific confluence of family, peer, school, community, and personal factors than with the demographic variables investigated here and conventionally understood as primary determinants. In subsequent analyses, using a 'composite capitals framework' derived from the theories of Bourdieu (1986) and Becker and Tomes (1986), we will be exploring how cultural, social, economic, and human capitals interact to impact on the educational and career aspirations of students across all of the variables considered in this preliminary analysis.

\section{Conclusion}

Collectively, our analyses demonstrate both the complexity of students' career aspirations and some of the challenges associated with undertaking this kind of research. Each of the variables examined and measures used in this paper poses conceptual and methodological questions, including how we define each variable and how we ask students about what they want to do or be, or what kinds of work appeals to them and why. These apparently simple questions have no simple answers. We have, however, demonstrated that some conventional understandings about the relationship of age and SES to career aspirations are unfounded. These analyses caution against both simplistic policy directives and superficial educational interventions in a field where complexity prevails.

Acknowledgments The authors wish to acknowledge the support provided in the preparation of this manuscript by Rosie Barron, Nathan Berger, Hywel Ellis, Leanne Fray, Elizabeth McDonald, Dan Perell, Claire Wallington, and Craig Walsh. We also acknowledge the important funding for the study provided by the Australian Research Council and the New South Wales Department of Education and Communities. Finally we are most grateful to the students and their parents, carers, and teachers for their participation in this project.

Open Access This article is distributed under the terms of the Creative Commons Attribution License which permits any use, distribution, and reproduction in any medium, provided the original author(s) and the source are credited. 


\section{References}

Australian Curriculum, Assessment and Reporting Authority (ACARA). (2012). Data standards manual: Student background characteristics. Sydney: Author. Retrieved Sept 9, 2014 from http://www.acara. edu.au/verve/_resources/DSM_1.pdf.

Australian Curriculum, Assessment and Reporting Authority (ACARA). (2013). Guide to understanding 2012 Index of Community Socio-educational Advantage (ICSEA) values. Sydney: ACARA. Retrieved Sept 9, 2014 from http://www.acara.edu.au/verve/_resources/Guide_to_understanding_ 2012_ICSEA_values.pdf.

Baker, W., Sammons, P., Siraj-Blatchford, I., Sylva, K., Melhuish, E. C., \& Taggart, B. (2014). Aspirations, education and inequality in England: Insights from the effective provision of preschool, primary and secondary education project. Oxford Review of Education, 40(5), 525-542. doi:10.1080/03054985.2014.953921.

Becker, G. S., \& Tomes, N. (1986). Human capital and the rise and fall of families. Journal of Labour Economics, 4, S1-S39.

Bourdieu, P. (1986). The forms of capital. In J. Richardson (Ed.), Handbook for theory and research for the sociology of education (pp. 241-258). New York: Greenwood Press.

Bowden, M., \& Doughney, J. (2010). Socio-economic status, cultural diversity and the aspirations of secondary students in the Western Suburbs of Melbourne, Australia. Higher Education, 59(1), 115-129. doi:10.1007/s10734-009-9238-5.

Bradley, D., Noonan, P., Nugent, H., \& Scales, B. (2008). Review of Australian higher education: Final report. Canberra: Department of Education, Employment and Workplace Relations. Retrieved Sept 9, 2014 from http://www.mq.edu.au/pubstatic/public/download.jsp?id=111997.

Cardak, B., \& Ryan, C. (2009). Participation in higher education in Australia: Equity and access. Economic Record, 85, 433-448. doi:10.1111/j.1475-4932.2009.00570.x.

Commonwealth of Australia. (2009). Transforming Australia's higher education system. Canberra: Commonwealth of Australia.

Cummings, C., Laing, K., Law, J., McLaughlin, J., Papps, I., Todd, L., \& Woolner, P. (2012). Can changing aspirations and attitudes impact on educational attainment? A review of interventions. New York, UK: Joseph Rowntree Foundation.

Dalley-Trim, L. (2012). Young women's dismissal of the influence of gender upon their future life trajectory as played out in "New Times". Australian Educational Researcher, 39, 193-205. doi:10. 1007/s13384-012-0058-8.

Gale, T., \& Parker, S. (2013). Widening participation in Australian higher education: Report to the Higher Education Funding Council of England (HEFCE) and the Office of Fair Access (OFFA), England. Leicester, UK: CFE Research.

Ginzberg, E. (1952). Toward a theory of occupational choice. Occupations, 30, 491-494. doi:10.1002/j. 2164-5892.1952.tb02708.x.

Gorard, S., See, B. H., \& Davies, P. (2012). The impact of attitudes and aspirations on educational attainment and participation. New York: Joseph Rowntree Foundation.

Gottfredson, L. S. (1981). Circumscription and compromise: A developmental theory of occupational aspirations. Journal of Counseling Psychology Monograph, 28, 545-579.

Hawkins, C. (2014). The Graduate, the globetrotter and the good samaritan: Adolescent girls' visions of themselves in early adulthood. Australian Educational Researcher. Advance online publication. doi:10.1007/s13384-014-0149-9.

James, R. (2002). Socioeconomic background and higher education participation: An analysis of school students' aspirations and expectations. Canberra: Evaluations and Investigations Programme Higher Education Group.

Khattab, N. (2005). The effects of high school context and interpersonal factors on students' educational expectations: A multi-level model. Social Psychology of Education, 8(1), 19-40. doi:10.1007/ s11218-004-8976-6.

Kilpatrick, S., \& Abbott-Chapman, J. (2002). Rural young people's work/study priorities and aspirations: The influence of family social capital. Australian Educational Researcher, 29(1), 43-67. doi:10. 1007/BF03219769.

Lee, V. E. (2000). Using hierarchical linear modeling to study social contexts: The case of school effects. Educational Psychologist, 35(2), 125-141. doi:10.1207/S15326985EP3502_6. 
Marjoribanks, K. (2003). Learning environments, family contexts, educational aspirations and attainment: A moderation-mediation model extended. Learning Environments Research, 6(3), 247-265. doi:10. 1023/A:1027327707647.

Marks, G., Fleming, N., Long, M., \& McMillan, J. (2000). Patterns of participation in Year 12 and higher education in Australia: Trends and issues (LSAY Research Report No. 17). Retrieved Sept 9, 2014 from Australian Council for Educational Research website: http://research.acer.edu.au/lsay_ research/66.

McMahon, M., Carroll, J., \& Gillies, R. M. (2001). Occupational aspirations of sixth-grade children. Australian Journal of Career Development, 10(1), 25-31. doi:10.1177/103841620101000107.

McMahon, M., \& Rixon, K. (2007). The career development of rural Queensland children. Australian Journal of Career Development, 16(2), 39-50. doi:10.1177/103841620701600207.

McMillan, J., Beavis, A., \& Jones, F. L. (2009). The AUSEI06: A new socioeconomic index for Australia. Journal of Sociology, 45(2), 123-149. doi:10.1177/1440783309103342.

McMillan, J. H., \& Schumacher, S. (2009). Research in education: Evidence-based inquiry (7th ed.). Upper Saddle River, NJ: Pearson Education.

Monson, R. (1990). Occupational epidemiology (2nd ed.). Boca Raton, FL: CRC Press.

Naylor, R., Baik, C., \& James, R. (2013). Developing a critical interventions framework for advancing equity in Australian higher education. Retrieved July 25, 2014 from National Centre for Student Equity in Higher Education website: https:/www.ncsehe.edu.au/wp-content/uploads/2014/09/ Critical-Interventions-Framework-20-August-2013.pdf.

Osborne, J. W. (2006). Bringing balance and technical accuracy to reporting odds ratios and the results of logistic regression analyses. Practical Assessment Research and Evaluation, 11(7), 1-6.

Perry, L. (2014). The scholarship fig leaf: They won't improve access for all. Retrieved June 4, 2014 from http://theconversation.com/the-scholarship-fig-leaf-they-wont-improve-access-for-all-27321.

Preacher, K. J., Zhang, Z., \& Zyphur, M. J. (2011). Alternative methods for assessing mediation in multilevel data: The advantages of multilevel SEM. Structural Equation Modeling, 18(2), 161-182. doi:10.1080/10705511.2011.557329.

Robinson, D. H., \& Levin, J. R. (1997). Research news and comment: Reflections on statistical and substantive significance, with a slice of replication. Educational Researcher, 26(5), 21-26. Retrieved Dec 18, 2014 from http://www.jstor.org/stable/1176589.

Schuetze, H. G., \& Slowey, M. (2002). Participation and exclusion: A comparative analysis of nontraditional students and lifelong learners in higher education. Higher Education, 44(3-4), 309-325. doi:10.1023/A:1019898114335.

Thomas, D. R. (2003). A general inductive approach for analyzing qualitative evaluation data. American Journal of Evaluation, 27(2), 237-246. doi:10.1177/1098214005283748.

Trewin, D., Trewin, D. J., \& Pink, B. N. (2006). ANZSCO: Australian and New Zealand standard classification of occupations. Canberra: Australian Bureau of Statistics/Statistics New Zealand.

Jennifer Gore is a Professor in the School of Education at the University of Newcastle, where her work is affiliated with the Centre of Excellence for Equity in Higher Education. Jenny currently leads the Teachers and Teaching Research Program at the University and is Co-Editor of the international journal, Teaching and Teacher Education. Her educational and research interests have consistently centred on quality and equity, including studies of teacher socialisation, power relations in teaching, reform of teaching and teacher education, and teacher development.

Kathryn Holmes is a Senior Lecturer in the School of Education at the University of Newcastle. A core member of the Teachers and Teaching Research Program and an affiliate of the Centre of Excellence for Equity in Higher Education at the University, Kath is also Co-Editor of the international journal, Teaching and Teacher Education. Her research interests focus on the application of technology in education, increasing participation in STEM disciplines, and improving quality, equity, and access in schools and higher education.

Max Smith is a Professor in the School of Education at the University of Newcastle. In addition to his role as Deputy Head of School for Research Development, Max is a core member of the Teachers and Teaching Research Program at the University, and Co-Editor of the international journal, Teaching and 
Teacher Education. With particular emphasis on quality and equity, his work is closely aligned with the Centre of Excellence for Equity in Higher Education. Max's research interests extend from child development and pedagogy in the 21 st century to measurement and evaluation in education.

Erica Southgate is a Senior Lecturer and researcher in the School of Education at the University of Newcastle, where she is also affiliated with the Centre of Excellence for Equity in Higher Education. She has expertise in conducting qualitative social research in the areas of education and health, with a focus on social disadvantage and marginalisation. Erica's recent work includes a study of pathways into medicine for disadvantaged students and analysis of the widening participation agenda in higher education.

Jim Albright is a Professor in the School of Education at the University of Newcastle and an affiliate of the Centre of Excellence for Equity in Higher Education. Editor-in-Chief for Educational Science, Jim's interests range from literacy education and curriculum theory and design to professional learning and school reform. Recently, his work has focused on developing teacher capacity across subject areas through the building of conditions needed in schools for innovative teaching and improved student performance. 